\title{
Learning from Interactive Museum Installations About Interaction Design for Public Settings
}

\author{
Eva Hornecker \\ HIT Lab NZ \\ University of Canterbury \\ Private Bag 4800, Christchurch 8004, NZ \\ eva.hornecker@hitlabnz.org
}

\begin{abstract}
This paper reports on the evaluation of a digitallyaugmented exhibition on the history of modern media. We discuss visitors' interaction with installations and corresponding interaction design issues, drawing on results from analysis of logfiles, interviews, and observation in the museum. We see this as an exploration into interaction design of interactive installations for public settings, using the evaluation as a case study on what makes an installation engaging and how it can provide an engaging experience for groups.
\end{abstract}

\section{Author Keywords}

installations; interaction design; user experience; field study; public settings; physical interfaces; groups

\section{ACM Classification Keywords}

H5.m. Information interfaces and presentation (e.g., HCI): Miscellaneous.

\section{INTRODUCTION}

Museum spaces nowadays are increasingly augmented with digital technology. While some systems primarily provide context-sensitive, dynamic, and multimodal information (Oppermann and Specht 1999), others offer novel services or enable new kinds of activities, such as treasure hunts (Fraser et al, 2003), the collection of souvenirs and photos (Fleck et al, 2002), or change exhibition design and content with interactive exhibits (Ciolfi, 2004, Heath et al, 2002). Public spaces and museums as application areas and settings of use have turned into a respected field of research for HCI.

In summer 2003 the Austrian Technical Museum Vienna (TMW) opened medien.welten, a long-term exhibition on media history. It combines traditional object exhibits, computer-enhanced hands-on exhibits, and a large space dedicated to modern media. As part of the exhibition visitors can buy a smartcard that stores collected or selfcreated data into a 'digital backpack' that visitors can later-on access online. In mid 2003 the igw institute of TU Vienna was contracted for an evaluation. The museum wanted us to evaluate the overall exhibition and to explore the utility of automatically generated data for

OZCHI 2006, November 20-24, 2006, Sydney, Australia. Copyright the author(s) and CHISIG

Additional copies are available at the ACM Digital Library (http://portal.acm.org/dl.cfm) or ordered from the CHISIG secretary (secretary@chisig.org)

OZCHI 2006 Proceedings ISBN: 1-59593-545-2

\author{
Matthias Stifter
}

Institute of Computer Graphics and Algorithms

Vienna University of Technology

Favoritenstr. 9-11, A-1040 Vienna, Austria

stifter@cg.tuwien.ac.at

tracking visitors' movement and interaction patterns. Furthermore we were to assess visitors' attitudes towards the smardcard and its actual usage. We chose a multimethod strategy, complementing quantitative dataanalysis with qualitative, ethnographically oriented methods. The project resulted in a 118-page project report completed in March 2004 (Hornecker and Stifter, 2004) and the second author's diploma thesis (Stifter, 2005).

Traditionally, museums aim for throughput and installations are designed so as to only include enough interaction to get the point of the exhibit across (c.f. Harrison, Minneman and Balsamo, 2001), intentionally providing shallow functionality. But in the medien.welten the interactive media itself is part of the exhibition 'content' that visitors should experience and engage with; interaction with an installation is part of its 'message'. Therefore, evaluators and curators agreed to rate extended engagement with exhibits as positive. Having a more general research interest in interaction design for public settings, we furthermore advocate exploiting the full potential of interactive media in these settings, and to allow for extended and repeated engagement.

In a previous publication (Hornecker and Stifter, 2006) we have reported on the evaluation of the smartcard and on our experiences with the multi-method evaluation strategy. Here we focus on results concerning interactive exhibits, interpreting success of an exhibit along a range of criteria. The TMW wants to offer everybody something of interest. But besides of an entertaining experience, museums aim to educate the public. As indicated above, we regard prolonged (or repeated) interaction as positive, indicating that visitors find an exhibit engaging and interesting. Somewhat orthogonal to duration is intensity of engagement (someone can merely play around or be mentally engaged with content). Other criteria are for example, if an exhibit attracts many people, if it exposes them to topics they are unfamiliar with, or offers something for those with specific interests who otherwise might leave the exhibition disappointed. We see this as an exploration into interaction design of interactive installations. Striking observations were for example how different types of exhibits attract different types of visitor, and how they get used in different ways. Our study highlights the role of physical handles and interfaces in engaging a diversity of visitors across age and interest groups and draws attention on the effects of the physical set-up on the emerging constellations of visitors around an installation and on interaction patterns with it. We found 'active' media to be particularly 


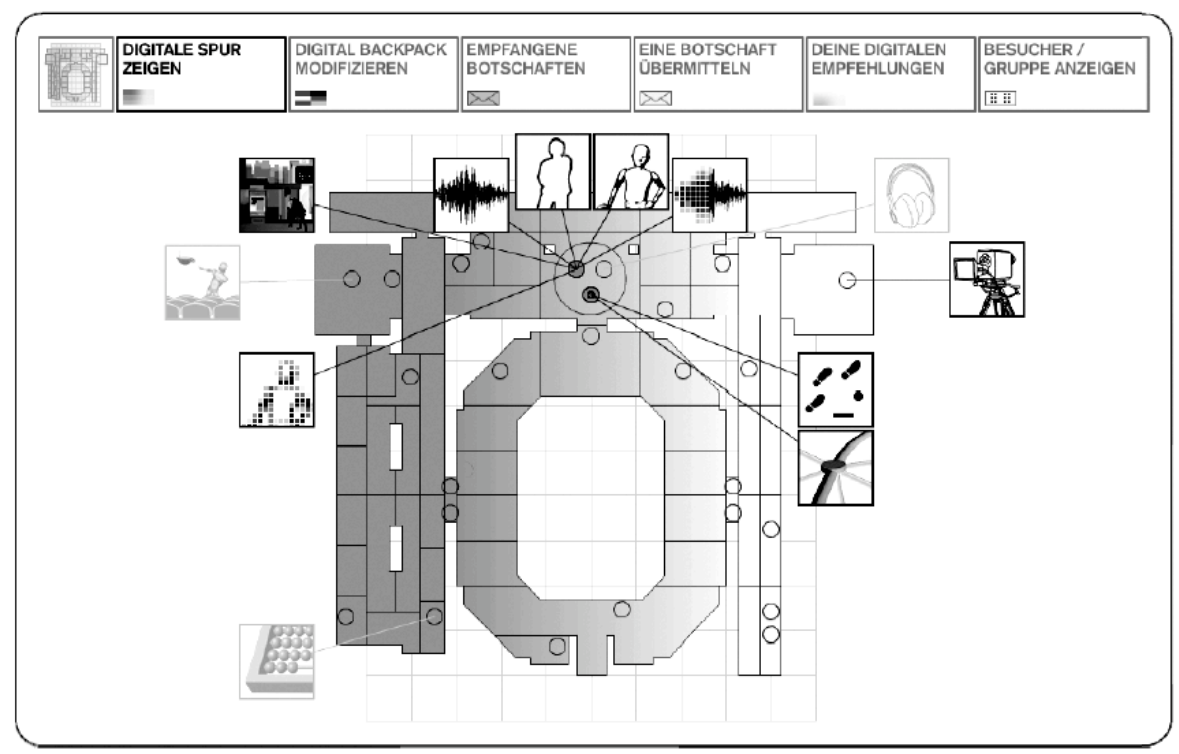

Figure 1. The digital backpack shows a map of the exhibition. Circles designate installations or terminals. Dark icons indicate stored data, grey icons unexplored exhibits. Bookmarks from the media.matrix are shown with the left icon in the menu.

successful. We take from this as inspiration for interaction design that the content of installations can consist of the users' very own activity, both in creating novel content and in providing a performance that is watched by others and simultaneously provides the core experience for the active person.

\section{THE EXHIBITION}

A central goal of the medien.welten exhibition is to arouse interest and understanding for modern media in visitors of all age groups and to increase awareness of possibilities and risks of the media society (Moritsch and Pensold, 2003). The exhibition is structured in three parts, reflected in its layout (see figure 1). The history of transmission media is shown in the right wing while the left wing presents storage and calculation media. Thematic islands start chronologically at the entrances (bottom). The convergence into today's digital media is presented in the large 'digital room' that connects the top far ends of both wings.

Traditional object exhibits are placed next to interactive exhibits for hands-on experience. An example for a digitally-augmented hands-on exhibit is the Abacus (figure 2) which guides visitors through calculation examples by providing feedback and instructions on the monitor behind the tangible input space. Two other augmented hands-on exhibits deal with telegraphy and allow Morse coding, either with an alphabet wheel or a
Morse ticker (figure 3), and simulate optical telegraphy. Other installations are purely screenbased. Five touch screens offer a guide system providing an overview of the exhibition and supporting exploration of one's digital backpack, in case the smartcard has been purchased. Six information terminals (the 'media.matrix') are installed throughout the exhibition and allow exploration of the history of media evolution, organized in a matrix across themes and eras.

Many installations are placed in the 'digital room'. Most popular is the blue screen TV Newsroom studio (figure 6 upper row). Here visitors are led through reading the news. After a test run they can videotape themselves. The video is overlaid with the Austrian TV news intro and logo and then shown in public on a big screen. Well-liked by children and families are the digitisation booths that allow saving photos and sound samples (figure 2). The ORF archive (a touch screen terminal) offers a selection of Austrian TV and radio clips from the last 50 years. Furthermore ten PC terminals offer a range of applications, e.g. networked games, simulations, image processing and edutainment programs. Here one can go on processing photo and sound samples. Digital media produced by visitors are fed into these applications, visible to others until replaced by new items.

The inner space of the exhibition, surrounding a glassroofed court, contains three further installations. The 'transparent human' shows fragmented parts of backpack content on a glass curtain. 'Global Storage' and 'Global Net' consist of two large projections each. One of these shows a globe which slowly turns and allows selecting cities with laser wands from the globe (see figure 6 lower row). Using the laser wand, the globe can also be rotated. Material from digital archives in selected cities is downloaded and 'floats' onto the second screen where it can be selected and opened by pointing with a wand.

\section{THE EVALUATION}

Due to the broad range of issues to be evaluated, we chose a multi-method strategy, which complements quantitative data-analysis with qualitative,
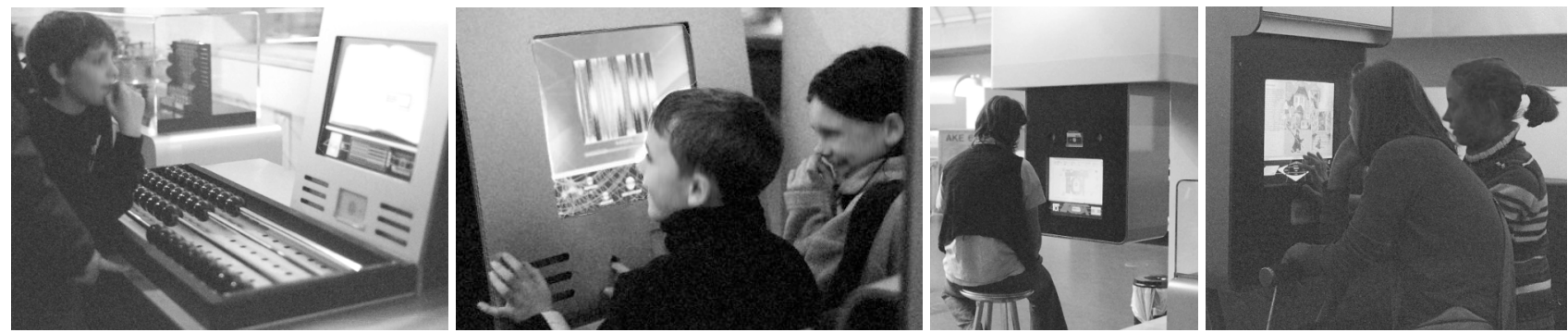

Figure 2. A family calculating with the Abacus and children in the digitization booth. Guide system and media.matrix 
ethnographically oriented methods (Blomberg et al, 1993, Mackay, 1998). The curators for example wanted information on interaction patterns with specific exhibits as well as an overview of which installations visitors liked best. We were to investigate usability problems to be resolved, visitors' interactions with the smartcard and their perception of this service. Furthermore the museum was interested in testing the feasibility and utility of using automatically generated data to track visitor interaction.

Smartcard tracking data, digital backpack content and logfiles of computer-enhanced exhibits were statistically analysed by the second author. Logging interaction events of exhibits from October 2003 to February 2004 yielded 35120 anonymous and 2253 card sessions. Furthermore 978 card profiles (created from July 2003 to February 2004) were available for analysis. The first author supervised the quantitative analysis and conducted the qualitative study, involving $\sim 16$ hours of observation and 30 interviews with visitors. Findings were continually discussed. That way observations helped to interpret patterns found in the data, created further questions for data analysis or highlighted inaccuracies and blind spots of data capture. Data analysis on the other hand created new issues to focus on in observation. We found findings from observation and data analysis to augment and predominantly reinforce each other, observation providing insight into underlying causes of data patterns, while data analysis proves that the observed behaviours generalize to the majority of visitors.

Besides of 16 hours of open observation in the exhibition we conducted and analyzed 30 semi-structured interviews of 5-10 minute length with a representative sample of visitors (children, couples, pupils, senior citizens, teachers, families...). Most interviews took place when visitors left the exhibition. Interviews were taped, transcribed, and analyzed according to interview questions and emerging recurrent themes. Questions focused on the motivation to buy or not buy a card, the experience of the exhibition and the card, and suggestions for improvement.

Participant observation (usually 2-3 hours per visit, extended over several months) was oriented by ethnographic approaches (Blomberg et al, 1993), taking field notes, subsequently extracting further research questions and observational categories. It was scheduled so as to cover high- and low-frequented times and diverse visitor types, including typical days for families or school classes on day trips. Visitors were informed about the research through notices at the entrances. Observations and atmospheric impressions were documented with a series of photos. Observation took place at a distance so as not to intrude. If informal conversations evolved, it became possible to walk along with visitors and to observe more closely. Field notes for example summarized the distribution of visitors within the exhibition while the observer was walking round, what people were doing and briefly categorizing them (age, gender, size and type of groups). Often we followed a range of visitors throughout their visit from a decent distance, noting down their interactions and overheard comments and conversations concerning the exhibits. At other times we focused on one exhibit for a while, observing the flow of visitors and interactions with it.

\section{EVALUATION RESULTS}

The evaluation looked at several aspects of visitors' behavior. We pointed out usability issues and problematic aspects of interaction with the smartcard, particularly the complexity of the application. Furthermore, we investigated which exhibits attracted visitors' engagement, how long they would interact and how deep they explored them and identified patterns of interaction behaviors. We also compared data from smartcard users with 'anonymous use sessions' for most exhibits.

We will first give a short overview of visitor types and their interests, serving as background for further discussion. Then we will provide an overview of how visitors distributed their 'attention' and how deep they would explore exhibits, starting to unravel what makes an installation engaging and successful. Most successful in terms of attracting many visitors and long interaction sessions proved to be the hands-on exhibits, which engaged all types of visitors, and installations that required active participation. At last we describe our findings of how the set-up of exhibits drew different sizes of visitor groups, before turning to the final discussion.

\section{Types of visitors}

For our evaluation it was necessary to know the target group of users and how it is differentiated. Statistics tell us that visitors to technical museums are younger than
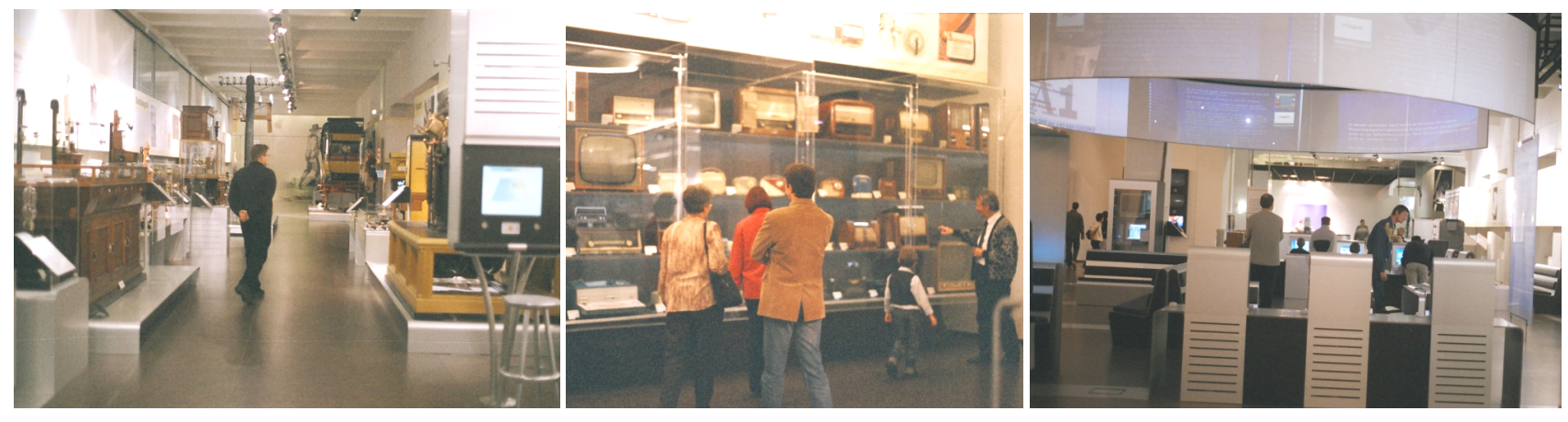

Figure 3. Different areas of the exhibition: The corridor for transmission media, where the telegraphy installation is located (not visible), in the foreground a media.matrix terminal. The 'shopping window' with electronic appliances from 30's to nowadays covers the back wall of the 'digital room'. The 'digital room itself - back at the end is the TV Newsroom studio. 
e.g. average visitors to art museums and predominantly male. Reflecting on 16 hours of observation and the 30 interviews we inferred a set of distinct interest profiles. Some visitors, in particular the elderly, have a nostalgic interest in objects from their youth. Others are interested in the history of devices or history in general, while some are interested specifically in new media and computers. Young children were primarily interested in gaming in the digital room. We found that a big proportion of people visit the exhibition only as a part of the entire museum - often as the last floor they get to. These we termed the ' 15 minute strollers' as they spend 10 to 15 minutes. As we will go on to present, there were salient differences in which visitors engaged with certain exhibits. Understanding these differences is essential for planning such a setting if one wants to provide all kinds of visitors/users with a valuable and engaging experience. Our evaluation e.g. provided evidence that historically interested visitors, who often wished to take background information home for further study and would have liked to buy the smartcard for these purposes, were not served well with the range and type of content they could actually collect (see Hornecker and Stifter, 2006). This finding has resulted in the addition of further content and redesign of some content since our study.

\section{Findings on Exhibits - Interaction patterns}

Despite of small differences regarding which exhibits smartcard owners were spending more time with than the public in general, the statistics of card users' sessions illustrate the general pattern. A session starts when a card is registered (a user laying it on the reader tray or being within 70 centimeters range of a long-distance reader) and ends when the visitor removes it or walks out of tracking distance. The upper graph in figure 5 shows the median duration of use (which is up to four minutes) for different installations. Below we see how long all smartcard users together (summed up) engaged with exhibits on a standard 9 hour day. This overall time is a result of the number of use sessions and their length. The lower graph clearly shows which exhibits were most popular in terms of being busy. The TV Newsroom studio, which during times of observation often had long waiting queues, was unrivaled (peak in the lower graph this is cards being actively used while videoing). At distance follow the two digitization booths (leftmost), where visitors could take photos and record sound samples, and then the Abacus and one of the applications running on the terminals in the digital room. Some exhibits, while not drawing many visitors and therefore being low in overall usage, managed to engage the few that interacted with them for considerable time. For example numerous applications on the terminals in the digital room competed with each other. This set of bars (on the left) is high in terms of median use duration but only average in overall usage.

Global Storage and Global Net have almost zero value in the lower graph, and few use sessions. Observation provided some indications to what caused this. The two installations were set in the inner circle of the exhibition. Visitors who walked through the digital room as part of

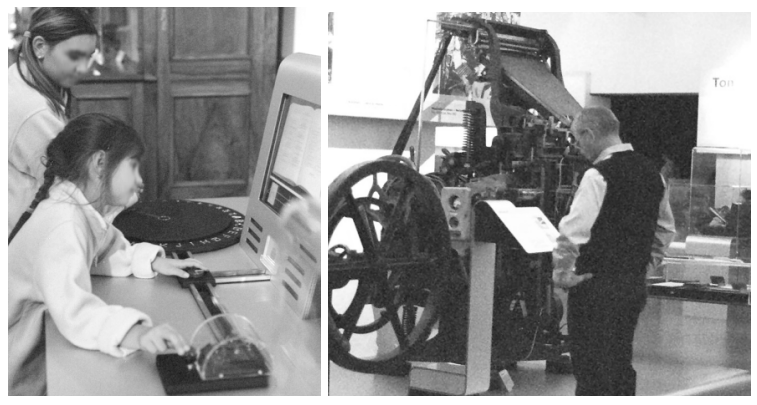

Figure 4. Two sisters at the Telegraphy hands-on exhibit and an elderly visitor interested in the printing press.

the outer circle holding approximately $80 \%$ of exhibits often did not notice them. We furthermore observed that it took most visitors at least two minutes to figure out how to use them. While many gave up quickly, others persisted and spent considerable time - we observed two groups exploring the installation for almost 15 minutes. The comment overheard from one group, "one must take his time", indicates that patience and an explorative mindset or mood were felt to be required.

Statistical data and observation point to usability issues providing a threshold to successful engagement with this installation. While the affordances of the laser pointer wands made it clear that one could point onto the projection screens, actually selecting something was not easy. The left screen showed a globe, which slowly turned around. Cities with databases the system could connect to were highlighted with a circle. One had to point into a circle for several seconds while the globe continued to turn. This means holding steady your hand while following the globe's movement, difficult enough for adults, but impossible for small children with limited motor-control. After selecting a city, the content of databases would slowly float onto the second screen. Sometimes the delay between selecting a city and the new items appearing meant that visitors had already gone on. Now the same usability issue reoccurred of the items circling on the screen, where one needed to select them to expand and open them. Once visitors got that far, they often were intrigued in exploring e.g. a San Francisco newspaper of the same day, or exhibits of a Berlin museum currently on display, and took their time.

The numeric result of low usage might lead to the conclusion that the installation failed to engage. Yet its

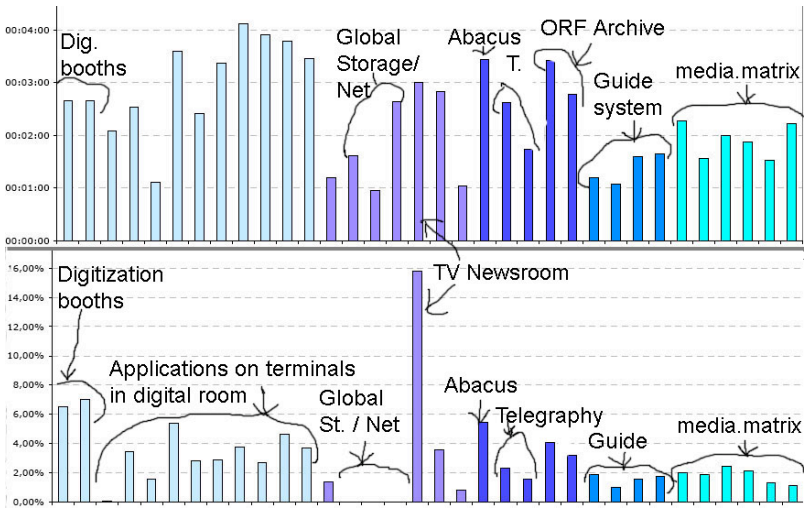

Figure 5. median duration of use per exhibit versus overall (summed up) usage of exhibits for all users (smartcards) 
low usage might be only due to usability issues that do not concern the overall value of the exhibit. E.g. by using more sophisticated algorithms for selecting targets, interaction with laser wands could be eased considerably. We need to remember that in a domain such as museums and public spaces with many competing objects, time pressure, and voluntary usage, a low threshold for interaction is essential - the first ten seconds need to provide an incentive to continue.

Besides of being fourth place in terms of overall usage, the Abacus was number three regarding the number of sessions by smartcard users. Overall it was active on average 20 to $30 \%$ of its daily runtime, sometimes up to $50 \%$. Most sessions took between three and four minutes (telegraphy sessions in comparison took 1,8 to 3 minutes). This made us wonder why an analysis of smartcard users' digital backpacks (here content is stored if the card is tracked) revealed only a tiny number of Abacus items. Observation showed that most visitors did not make it to the final steps of the somewhat lengthy calculation that they were stepped through, often only executing the first two steps. The calculation task then increasingly got difficult. It was obviously challenging, demanded concentration and reading instructions from the screen. Groups thus usually scaffolded each other. Finishing the calculation seemed to be experienced as satisfying, as indicated by visitors yelling 'Hurray - I made it' at the end. Overall, the Abacus can be considered a successful installation design in terms of allowing both for short and longer engagement, and the experience of challenge and success. Many visitors commented on the Abacus as a good exhibit and were satisfied on following the initial calculation steps.

The TV Newsroom studio, as said above, was the most popular exhibit in many respects. Interviewed visitors mentioned it frequently as a highlight of the exhibition; it was almost always occupied (and had the highest number of sessions of all exhibits), and the video came second place as content of digital backpacks. As we will discuss in later sections, we believe that its success is partly due to allowing for creative appropriation, providing a challenge (and reward) and being entertaining for groups.

Other installations were far less popular. On the far right in figure 5 we see a set of bars for the media.matrix, a large hypermedia-based information system organized in a matrix by topic and timeline, and for the guide system. These installations were used only for $2-5 \%$ of their daily runtime. In 16 hours of observation we saw 30 people using the media.matrix. Of these only seven took more than a minute, or followed on after the first two or three clicks (investigating what the exhibit would offer or randomly flicking pages). Logfiles verify that interaction sessions on average took one minute (whereas interaction with hands-on interactives lasted on average three to four minutes). The interviews taught us that most visitors were overwhelmed with too much text and would prefer to find information next to exhibits. This recalls the verdict from Ciolfi and Bannon (2002) that information kiosks don't allow for concentrating on exhibits and tend to distance visitors from the objects of interest (c.f. Kelly, 2000).
Furthermore the logfiles show that visitors usually only read one out of a series of four pages on a topic. Interestingly, some interviewed visitors said that they would be interested in the content, but would prefer to take it home. The museum visit is time-pressured and visitors want an engaging experience that is different from other places. As consequence, we have suggested to curators to provide the media.matrix content on a CD that visitors might buy, and to ease saving of content from matrix cells into one's digital backpack.

\section{The Success of Hands-On Exhibits}

We could observe a clear division into visitors that interact with computational media and those that focus on historic objects. Although they often seemed to be curious, it was in particular elderly visitors who more or less circumvented anything that looked like a computer (e.g. walking in a circle around a media.matrix terminal) and almost exclusively focused on the traditional exhibits. Children and young people, on the other hand, tended to spend most of their visit time in the digital room and in the TV Newsroom studio, and only rarely took notice of any object exhibits. Children often were disappointed that the media.matrix terminals did not offer games.

In terms of the educational aims of the exhibition this is a sad observation, as visitors tend to focus on the kinds of media that they are familiar with instead of getting exposed to unfamiliar ones. Besides of fear of technology and limited experience another reason for hesitating from computer-type installations might be techno-fatigue among adult visitors (Gammon, 1999). The only exhibits that succeeded in reaching all types of visitors were the hands-on interactive exhibits. The elderly did not hesitate to inspect exhibits such as the Abacus or the telegraphy station, even though these involved selecting examples from a screen and reading instructions from it. The same holds true for children and teenagers, which often spent considerable time here. Furthermore we could observe that visitors discerned and steered towards the hands-on exhibits quickly and from a distance, even if just walking through the exhibition. Most of the ' 15 minute stroll' visitors stopped for at least one or two hands-on exhibits.

As researchers interested in Mixed Reality and tangible interfaces, this provides us with evidence for the usefulness and appropriateness of these interface concepts for a museum context. Only the interactive hands-on exhibits succeeded in engaging all kinds of visitors regardless of age and interest profile. Thereby they also managed to expose them to something novel - elderly visitors were carried over the threshold of interacting with a computer and children explored a historic technical invention, such as Morse telegraphy. This shows that mixed media that combine haptic input devices with computational augmentation are effective in addressing diverse groups of visitors and arousing interest in unfamiliar topics. We know from the success of hands-on science museums that hands-on exhibits, which allow for bodily interaction, particularly attract children. Here we have found that such exhibits can also help people overcome potential inhibitions against computers and trigger less 'techno-fatigue'. 


\section{Visitor Activity Makes Installations Popular}

The most popular installations in terms of overall usage during runtime, number of sessions, and amount of content saved in digital backpacks all required intensive visitor activity. As described below, they either provided a challenging task, or they suggested and allowed creative appropriation. In stark contrast to this success of 'active media', the media.matrix, despite of its vast content and depth of thematic coverage drew little attention.

The Abacus and the telegraphy exhibits had a predefined task that users were led through. The Abacus in particular was experienced as challenging and had some visitors trying hard and spending extended time. Similarly the TV Newsroom studio gave instructions on the procedure and provided a News text to be read on a line by line display. While many tried hard to read this text accurately (often repeating several times), the studio was often appropriated creatively for visitors' own purposes. E.g. one family interviewed told us that they want to produce a video with a birthday greeting for their grandpa. While adults tended to read the news lines with stern voice (acting as News reader), children often misused the installation creatively. We saw groups taking turns in reading the lines or doing it in chorus, children singing a song, or imitating other forms of TV (talkshows, interviews). The video, after being saved, was replayed on a big screen, visible to everybody in the vicinity of the Newsroom. For some time it would also be replayed on TVs at an adjacent lounge before being replaced by newer clips. Interestingly, the public visibility of both the videos and the installation did not seem to inhibit most visitors. While reading the news text obviously was challenging and many visitors took several attempts until managing to get through without stuttering or laughing, most were intent to create a satisfying outcome.

The digitization booths proved to be pretty popular with card owners. Pictures from here took the biggest chunk of digital backpacks $(15 \%)$. There was no suggestion provided here on what to do (no defined task). Similar to the TV Newsroom studio, the booths were often used for personal messages (children recording 'Hello Mom, here are ...') or private images. The last ten pictures and sound samples are always kept alive in the system. We utilized these to get a random sample of images, which showed e.g. couples with faces close together or kissing, parents with children and playful images of children. Children often took extreme shots (very close, unusual angles, many children squeezing into the cabin together) or dressed up (e.g. as highwaymen with a mask).

\section{Different Types of Exhibits, Differing Group Sizes}

Although it is well known that most people visit museums in groups (Gammon, 1999; Grinter et al, 2002; Kelly, 2000), exhibit design often seems to assume a solitary visitor. Similar to the emergence of $\mathrm{CSCW}$ as a topic for HCI, tending for visitor groups is a relatively new issue in museum studies. In our evaluation a striking observation was how different types of exhibits drew different sizes of groups. The images used throughout this paper illustrate this finding. All exhibits were used by solitary persons. Many were also collaboratively engaged with by small groups (two to three people). A smaller number of installations were engaged with by somewhat bigger groups while only few afforded large groups.

Predominantly single users populated the terminals in the digital room, at most playing a connected game. The rare exception to this pattern were parents of small children who taught these how to use the computer.

The hands-on exhibits such as the Abacus and the telegraphy interactive exhibits were used intensely by individuals and often surrounded by small groups of up to four or even five people (figure 4,6). These frequently went through the tasks together, scaffolding each other by reading out aloud the instructions from the screen and discussing how many beads to move next. Family members in particular often aided children. The images illustrate that the observed group size was afforded as well as constrained by the physical set-up, that is the

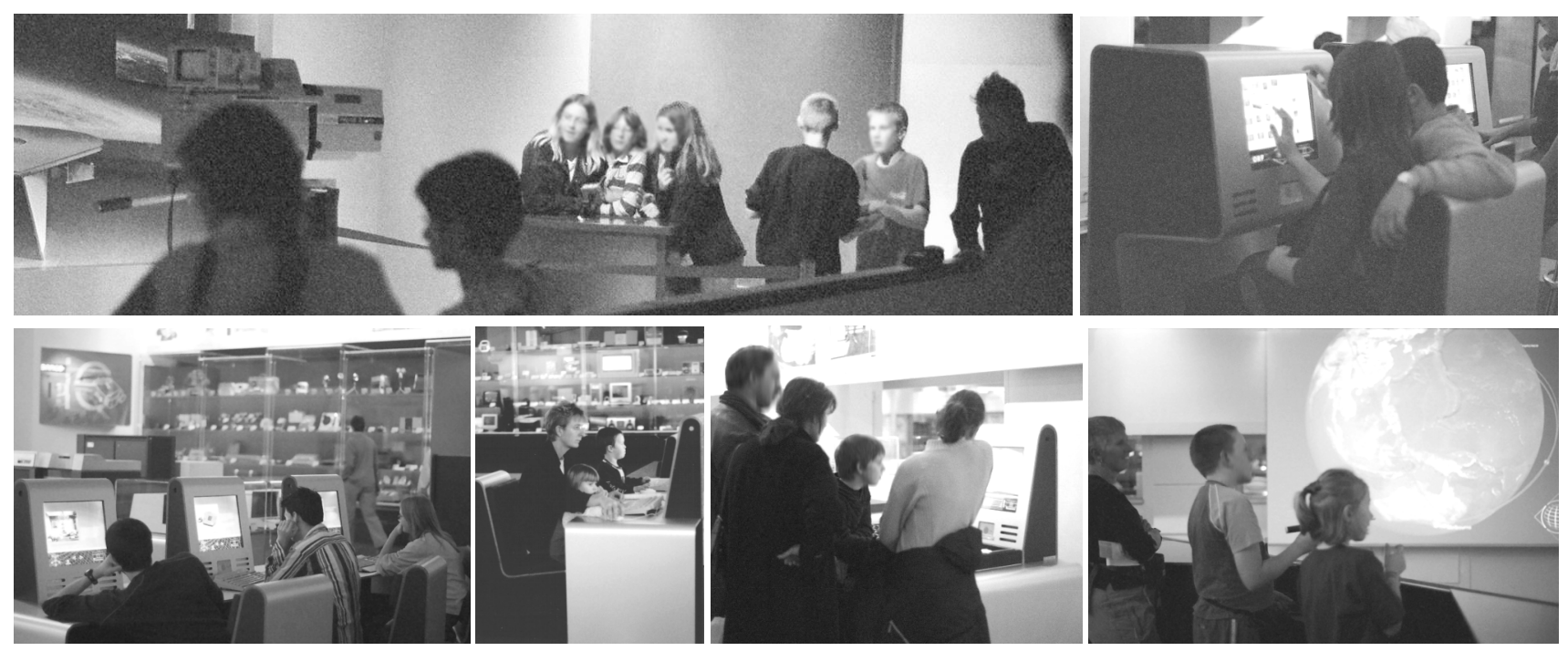

Figure 6. Upper Row: (left) The blue screen TV Newsroom studio is populated by a school class. (right) A couple engages in 'cooperative' TV watching and clip selection at the ORF-Archive. Lower Row: (left) Computer terminals in the digital room tend to be used by single persons, with the exception of parents with small children. (right) A family of four tries to solve the Abacus calculation examples and a family explores the Digital Net installation and retrieves items from online databases. 
provision of space for one's body and the visibility of the exhibit as well as of the interaction going on, which allows for scaffolding, commenting and discussing.

A similar pattern holds for the digitization booths, which allowed recording of an audio track and taking digital images. These were used by solitary people as well as by couples (often taking intimate shots) and groups. The latter tended to be children or teenagers taking fun-shots of their group. The size of groups was constrained by the size of the booth, which had a side and back wall, while the activity of recording or taking photos allows several people to participate. While figure 2 shows a pair of children audio recording, we also saw larger groups. Families and groups often used one of the adjacent computer terminals to post-process their images (saved with the smartcard) and switched places between booth and terminal repeatedly.

The ORF-Archive, a touch screen terminal with a seating bench, was used by solitary persons and pairs. This can be seen in figure 6 (upper row, right), which illustrates that the seating allowed at most two people to sit snug together. The touchscreen allows a quicker hand-over of control than a mouse, affording small groups. While seating here limits the size of a group, we believe that the screen furthermore would be too small for more than two people. Guide system and media.matrix (figure 4, right), in terms of observed group sizes, came somewhere between computer terminals and the ORF archive. They were predominantly engaged with by single visitors and relatively rarely by couples or small groups - if at all: these installations had a rather low frequency of usage as the overall evaluation revealed.

Only two exhibits afforded larger groups, the TV Newsroom studio and Global Net / Global Storage. Even though the latter were only rarely used, they proved to be entertaining for those visitors that took the time to explore them, and in tendency attracted groups. Figure 6 (lower row, right) shows a family exploring the hot spots on the globe. Group interaction here was afforded by the availability of several laser wands and by the large projection screens, creating a space that could easily host ten to fifteen people at once. The TV Newsroom studio overall was the only exhibit that afforded large group interaction and drew many visitors simultaneously. It is located at one end of the digital room, with an area of its own, and is highly visible from the entire room. Often large groups (families, school classes) were standing along the balustrade, along with other visitors. This balustrade is visible in figure 6 (upper row, left), and forms an ' $\mathrm{L}$ ' around the space where a huge TV camera is positioned, thereby partitioning the studio from the remaining room and providing a large space for observers. Here different groups of visitors came to talk with each other, something that happened rarely elsewhere. The activity of recording within this bluescreen studio provided entertainment for observers as well as something to talk about. Recording thus had elements of a 'performance' in public. Previous research has demonstrated that content that is visible for several people simultaneously can stimulate interaction between visitors (Grinter et al, 2002). In the case of the TV Newsroom studio the content is the public performance.

\section{DISCUSSION}

We see this as an exploration into interaction design of interactive installations. Our study highlights the role of physical handles and interfaces in engaging a diversity of visitors across age and interest groups. It further highlights the effects of different physical set-ups of installations on the emerging constellations of visitors around an installation and on interaction patterns. In (Hornecker, 2005) we have explained these effects as 'embodied constraints' and 'multiple access points'. We have seen that the content of installations can consist of the users' very own activity, either by creating novel (static) content or by giving a performance that is observed by an audience and simultaneously forms the core experience for the active person - part of the attraction of the TV Newsroom studio lies in overcoming the anxiety and properly acting as News speaker. For museums which draw larger groups we would thus suggest to provide installations that, similar to the digitisation booths and the TV Studio, allow creative adaptation and play as well as bodily movement (a success factor for children).

It is not the set-up or the interface on its own that provides engaging experiences. The content, or the appeal of topic and installation play a role as well. The familiar sight of the TV Newsroom sets both a challenge and an incentive. Digital Storage/Net put some visitors in an explorative mindset, curious about what to find, or trying to look at familiar places across the world. The Abacus triggered visitors' ambitions to solve the calculation. Besides of duration, engagement might differ in depth or intensity. Our study supports the importance of 'layering' of activities, as suggested by Gammon (1999). Installations can allow for different levels of engagement, allowing users to delve deeper and to explore aspects that the speedy user does not take notice of. Ciolfi and Bannon (2002) recommend allowing for short engagement, providing an early success experience and simple, small amounts of information, while increasing the complexity of information and/or activity with extended engagement. This early success experience is crucial for installations in public spaces, as the first few seconds decide on whether a user continues or turns to any competing object of attention.

We further note that stations allowing 'real' interactivity and creation of personal content (not just reading a given hypertext) were more intensely used (c.f. Kelly, 2000) than those with 'flat', predefined interaction. One of the proponents of 'Experience Design', Nathan Shedroff (2000) argued that the most engaging interactive experiences allow for productivity, creativity and/or communication, as these (a) are basic human motivations, and (b) inherently entail interaction by requiring openended activity of users. This leads us to suggest creative, communicative and personal interactions as a valuable avenue for installations in public spaces. Vice versa, museum installations seem a useful test bed for exploring these types of interactive experiences. 
Allowing for and supporting group interaction has been shown as imperative by recent studies which found that most museum visitors come in groups, want to have fun together, and that the group experience is a major aspect of their experience of the visit (Ciolfi and Bannon, 2002; Grinter et al, 2002; Aoki et al, 2002; Fraser et al, 2003; Heath et al, 2002). Installations with a physical setup that can host a small group, provides visibility and allows for handing over control or taking on different roles (such as reading from the screen or moving Abacus beads) proved successful in supporting group experiences. Heath et al (2002) explain that PC-based interactive installations with a traditional monitor, although entertaining, do not afford group interaction, as it is difficult for observers to discern where exactly the active user is looking at and what he/she is doing. Touchscreens provide better visibility to interactions and thus help groups to observe each other and to collaboratively engage. We surmise that the use of touchscreens at several hands-on exhibits as well as for media.matrix, guide system and ORF-archive engendered their use by small groups, while the computer terminals in the digital room were interacted with via keyboard and mouse. Following on from the success of the TV Newsroom studio we find it an interesting aspect for (museum) installations to transform visitor interaction into a public performance, which again is part of the exhibited content for others to see and to talk about.

\section{ACKNOWLEDGMENTS}

We thank TMW staff, especially Otmar Moritsch, and all visitors we worked with. This study was done at TU Vienna Institute of Design \& Assessment of Technology (igw). Jörg Hauber provided useful recommendations for structuring and focusing our writing.

\section{REFERENCES}

Aoki, P.M et al: Sotto Voce: Exploring the Interplay of Conversation and Mobile Audio Spaces. Proc. CHI'02. ACM Press (2002), 431-438.

Berkovich, M. et al.: Discovery Point: Enhancing the Museum Experience with Technology. Proc. CHI'03. ACM Press (2003), 994-995.

Bianchi, A., and Zancanaro, M.: Tracking users' movements in an artistic physical space. Proc. i3 Annual Conference (1999). 103-106 .

Blomberg, J. et al.: Ethnographic Field Methods and Their Relation to Design. In: Schuler, D., Namioka, A. (eds.) Participatory Design - Principles and Practices. Lawrence Erlbaum (1993), 123-155

Brown. B., et al. "Lessons from the Lighthouse: Collaboration in A Shared Mixed Reality System". Proc. CHI'03, ACM Press (2003), 577-584.

Ciolfi, L.; and Bannon, L.J.: Learning from Museum Visits: Shaping Design Sensitivities. Technical Report IDC-University of Limerick (2002).

Ciolfi, L. Situating 'Place' in Interaction Design. Enhancing the User Experience in Interactive Environments. PhD thesis University of Limerick (2004) http://richie.idc.ul.ie/luigina/LCThesis.pdf
Fleck, M. et al. Rememberer: A Tool for Capturing Museum Visits. Proc. UbiComp'02 (2002), 48-55.

Fraser, M., et al. Assembling History: Achieving Coherent Experiences with Diverse Technologies", Proc. ECSCW'03, Kluwer (2003), 179-198.

Gammon, B. How do visitors use computer exhibits? http://www.big.uk.com/knowledgebase/exhibits/compu ter_based_exhibits_v1.htm (1999) (read 12.6.2006).

Grinter, R.E. et al. Revisiting the Visit: Understanding How Technology Can Shape the Museum Visit. Proc. CSCW'02. ACM Press (2002), 146-155.

Harrison, S; Minneman, S,; and Balsamo, A. The How of XFR "experiments in the Future of Reading". Interactions. May+june (2001), 31-41.

Heath, C.; Luff, P.; Vom Lehn, D.; and Hindmarsh, J. Crafting participation: designing ecologies, configuring experience. Visual Communication 1(1) (2002). 9-33

Heinecke, A.M.: Evaluation of Hypermedia Systems in Museums. Proc. Int. Conference on Hypermedia and Interactivity in Museums ICHIM'95 / MCN'95. (1995)

Hornecker, E. A Design Theme for Tangible Interaction: Embodied Facilitation. Proc. E-CSCW 2005. Kluwer (2005), 23-43.

Hornecker, E., and Stifter, M. Evaluationsstudie Ausstellung medien.welten. Project report TU Wien \& TMW, March (2004). http://www.ehornecker.de/ Papers/EvaluierungsStudie_medienwelten_final.pdf

Hornecker, E. and Stifter. M. Digital Backpacking in the Museum with a SmartCard. Proc. CHI-NZ 2006. ACM DL (2006), 99-107.

Kelly, L.: Use of Computer Interactives in Museum Exhibitions: Literature Review. AMARC - Australian Museum Audience Research Centre (2000) www. amonline.net.au/amarc/pdf/about/complitreview.pdf (read 12.6.2006).

Kelly, L.: What Do People Do When They Visit A Museum? AMARC (2002) www.amonline.net.au/ amarc/pdf/research/visitorbehaviour.pdf (12.6.2006).

Mackay, W.: Triangulation within and across HCI disciplines. A Commentary. Human Computer Interaction Journal 3(13) (1998), 310-315.

Moritsch, O., and Pensold, W.: Das Projekt medien.welten - Die Ausstellung medien.weltenmedien.matrix-smart.card. forum. magazin technisches museum wien 02. (2003), pages 03-04, 05-06, 13, 15.

Oppermann, R., and Specht, M.: A nomadic Information System for Adaptive Exhition Guidance. Proc. ICHIM'99 (1999).

Stifter, M. Quantitative Analyse des Besucher-verhaltens - Evaluierung der Ausstellung medien.welten des Technischen Museums Wien mittels automatischprotokollierten Besucherinteraktionen. Diploma thesis TU Wien (2005).

Shedroff, N. Information Interaction Design: A Unified Field Theory of Design. In: Jacobson, B. (ed.): Information Design. MIT Press (2000), 267-292. 